\title{
Design and Implementation of a Telescope for Blind People based on an Atmega Controller
}

\author{
Fredy Criollo-Sánchez ${ }^{1}$, Cristian Mosquera-Sánchez ${ }^{2}$, Enrique Lee Huamaní ${ }^{3}$ \\ ${ }^{1}$ Electronic Engineering Program, Universidad de Ciencias y Humanidades, Lima-Perú, elvcriollos@uch.pe \\ ${ }^{2}$ Electronic Engineering Program, Universidad de Ciencias y Humanidades, Lima-Perú, ronmosqueras@uch.pe \\ ${ }^{3}$ Image Processing Research Laboratory (INTI-Lab), Universidad de Ciencias y Humanidades, Lima-Perú, \\ ehuamaniu@uch.edu.pe
}

\begin{abstract}
In this research a design of glasses for blind people has been developed using an Atmega controller (Arduino nano) and a sensor (ultrasonic), people who have visual problems struggle all the time with the problem of mobility, that is, moving from one point to another without having accidents with the obstacles in their way. The aim of this research is to make an electronic device capable of detecting obstacles for blind people, in order to offer blind people the possibility of having a new resource to help them detect the obstacles and thus have better movement. For the project, an Arduino nanocontroller was used, an ultrasonic sensor as an obstacle detector, a buzzer to generate a warning sound and a program developed based on the calculation of the distance to the obstacle. This research will focus on the following stages that correspond to evaluate the main difficulty of a blind person, the development of the device, development of the Arduino programming, tests of the functionality of the device, implementation and conclusions.
\end{abstract}

Key words: Arduino, Device for blind people, microcontroller, ultrasonic sensor.

\section{INTRODUCTION}

Today in our society blind people have difficulties in their daily life to mobilize and this is due to several factors, according to the population study was taken as reference 4849 people, where the cataract was the main cause of blindness with $58 \%$ followed by glaucoma in $13 \%$ [1].

Therefore, the reasons that cause this type of disability are mainly due to illnesses and accidents that occur in the course of their lives and others that are poorly formed during pregnancy. This disability allows blind people to develop their other senses more efficiently, such as touch, smell and perception [2].
Since visual impairment is described as a worldwide problem, the development of an object detection device for blind people is being considered. The main reason that took us to do this research is to be able to put into practice the development of this idea, taking it to the experimental stage, starting with the creation of schematics, electrical simulations, improving the prototype, making the implementation and obtaining results, so we will be able to provide help to blind people with low economic resources [3].

The objective of this research is to design an object detection device for blind people, using low-cost electronic components that are versatile in daily use. It also aims to provide greater security of movement in their daily lives.

\section{DESIGN CRITERIA}

This design is intended to provide a solution to the problem of blind people using inexpensive materials that are available on the market. The following criteria have been used to design this device.

- Evaluate possible existing designs

- Ensure that the device works properly

- Low-cost materials

- Lightweight and portable

The project consists of a design of an object detection device for blind people, which will use a programmable controller module (Arduino) plus an ultrasonic sensor that has a transmitter and receiver at the same time making it send a sound pulse not audible by the human ear (transmitter) and measure the time it takes the sound to reach the obstacle, bounce and return to the sensor (receiver) when this happens a signal will be sent to the programmable card and this will send a pulse to activate an alarm so that the blind person can hear and know that there is an object in its path [4].

We used the criteria and bases of the project that was developed by Ontiveros in 2014. 4] The white cane has the function of giving security to the blind person, with this we took the basis for the development of the project. 
Fredy Criollo-Sánchez et al., International Journal of Emerging Trends in Engineering Research, 8(8), August 2020, 4394 - 4398

This device is developed with a distance of one and a half meters so that the blind person can react within seconds and hear the signal emitted from the device. The signal emitted by this device is in relation to the distance, the greater the distance the sound becomes more constant at the same tone, i.e. the intensity varies in relation to the distance.

\subsection{Design}

The device designed is basically an electronic circuit capable of detecting obstacles, measuring the distance and issuing an alarm when the sensor detects such obstacles.

\subsection{Materials}

Taking into account the costs and analyzing the characteristics that our design should have, this list of materials was taken.

- Arduino nano

- Ultrasonic sensor

- Buzzer

- Rechargeable battery

- Power supply (charger)

- Lens (frame)

\section{DEVELOPMENT}

In this project, easily accessible materials were used, both economical and user-friendly, as shown in Figure 1, we see the main components used, the Arduino nano, the ultrasonic sensor and the buzzer.

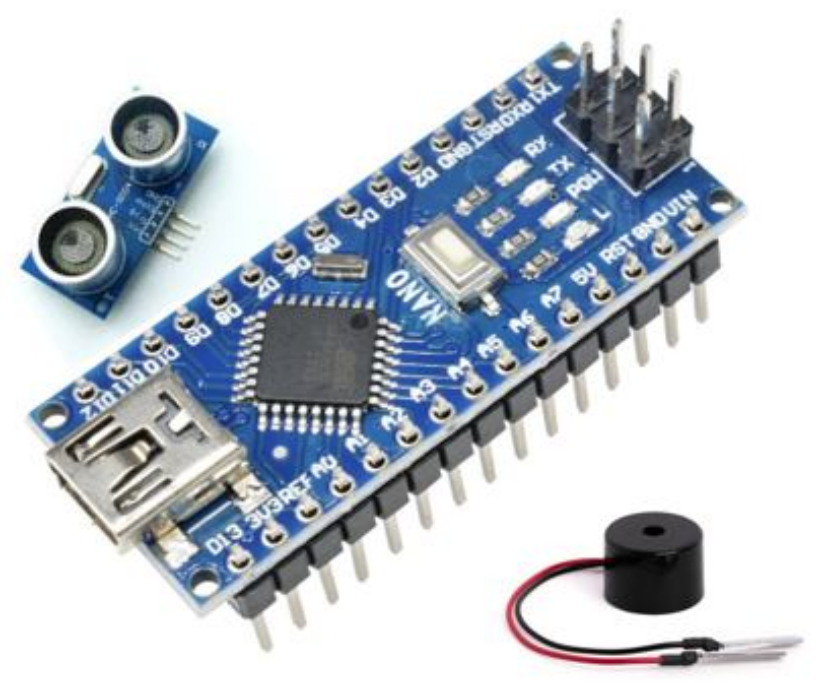

Figure 1: Electronic devices the Arduino nano, the ultrasonic sensor and the buzzer

\subsection{Design}

It is an economical microcontroller, we chose it for its features that has this device that is useful for this design, the card is free platform is not made any payment for using it and is compatible with most components has a simple programming in $\mathrm{C}++$ [5]. These are the characteristics of the Arduino nano for which we could choose this card [6], there are also researches such as [7] [8] that work with this same device.

\subsection{Ultrasonic sensor}

We chose this sensor because it measures distance with great precision by basically emitting sound waves that are not audible to the human ear. This device has a transmitter that emits a signal and a receiver that allows us to capture that signal and calculate how far away from the object this device is. It has 4 pins basically which are Vcc, Trig, Echo and GND.

The following are the characteristics of the ultrasonic sensor HC-SR04 with respect to Table 1. The Triger sends a signal upwards in the hope of having a reflected signal, i.e. the emitted signal hits an object and returns to the Echo which is the adapted ultrasonic receiver from [9].

Table 1: Electronic acteristics of the ultrasonic sensor hc-sr04

\begin{tabular}{|l|l|}
\hline \multicolumn{2}{|c|}{$\begin{array}{c}\text { CHARACTERISTICS OF THE ULTRASONIC SENSOR } \\
\text { HC-SR04 }\end{array}$} \\
\hline Working voltage & $5 \mathrm{v} \mathrm{DC}$ \\
\hline Working current & $15 \mathrm{~mA}$ \\
\hline Working frequency & $40 \mathrm{KHz}$ \\
\hline Maximum range & $4 \mathrm{~m}$ \\
\hline Minimum range & $2 \mathrm{~cm}$ \\
\hline Measuring angle & $15^{\circ}$ \\
\hline Trigger signal & pulse TTL $10 \mathrm{uS}$ \\
\hline Dimension & $45^{*} 20^{*} 15 \mathrm{~mm}$ \\
\hline
\end{tabular}

As we see in Figure 2, the working mode of the ultrasonic is basically the perception of the sound as the defines and bats do, a signal is emitted waiting for the echo that bounces off the obstacle, the sound signal is operating at $40 \mathrm{KHz}$ so it is more efficient in detecting all kinds of obstacles. 


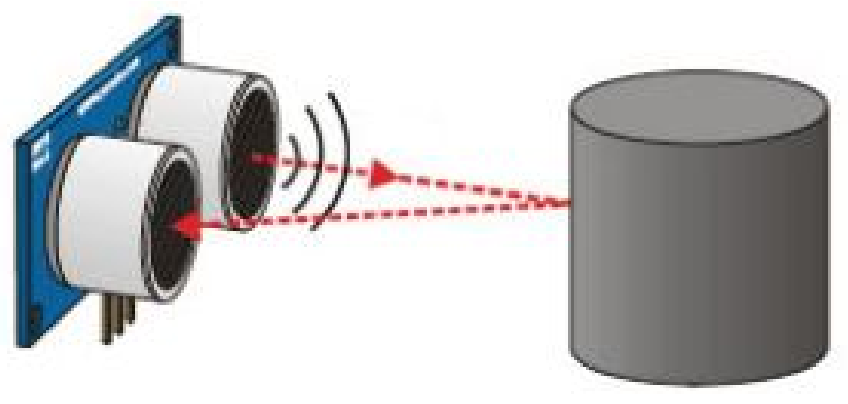

Figure 2: Electronic devices the Arduino nano, the ultrasonic sensor and the buzzer

\subsection{Buzzer}

This device is an electrostatic transducer that emits a single tone sound. It serves as a warning mechanism and is suitable for this design of an object detection lens.

The buzzer, internally is composed of two materials, an electromagnet and a sheet of steel. When a pulse is sent, a current enters and passes through the coil of the electromagnet, causing the steel plate to vibrate on the housing.

\subsection{Circuit design}

The design with respect to Figure 3 was made based on the pictographic diagram of our circuit shown in Figure 5, the connections between devices were according to our need for our design. The Arduino nano has digital and analog pins, voltage output, ground point, a receiver, transmitter among other functions but basically in this design we will base on these principles.

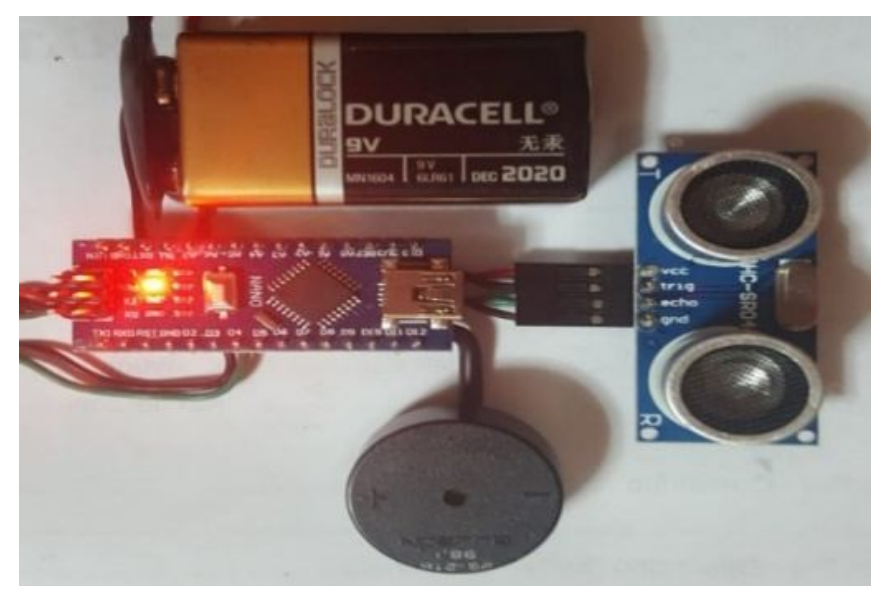

Figure 3: Connections between implement devices

Likewise, in the subject of blind people, a sound device was used since blind people generally present normal audible functions, sound is used as an indicator of the proximity of the obstacle, but with sound, making the blind person able to hear through it. Device and thus prevent tripping over an unknown object that is approaching it [10], its operation is shown in Figure 4 . This sends a pulse of sound that is not audible to the human ear (transmitter) and measures the time it takes for the sound to reach the obstacle, bounce back and return to the sensor (receiver).

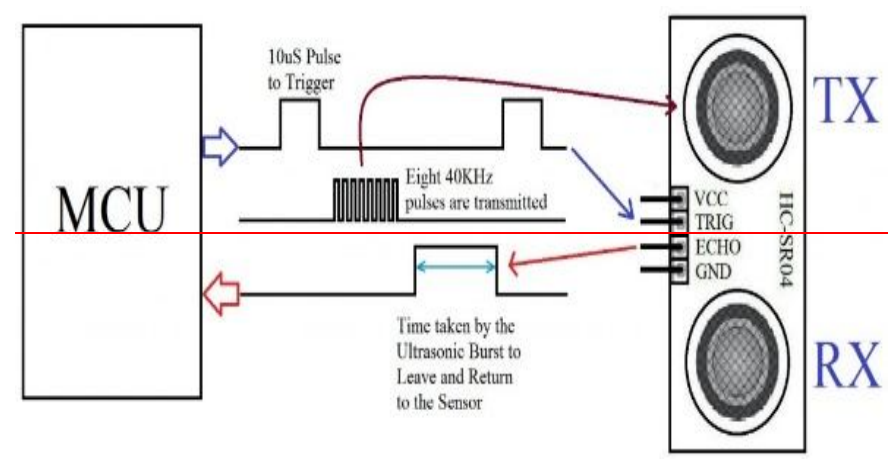

Figure 4: Sent from the signal to the module

The program developed for the design is based on the calculation of the distance, allowing to collect information through the ultrasonic sensor and this gives us an answer to apply it in the difficulty that blind people have.

\subsection{Circuit hardware design architecture}

The design is composed of an ultrasonic sensor, an Arduino module in charge of processing the signal and a buzzer in charge of emitting the sound when an object is detected. This device will be powered by a rechargeable battery as shown in Figure 5.

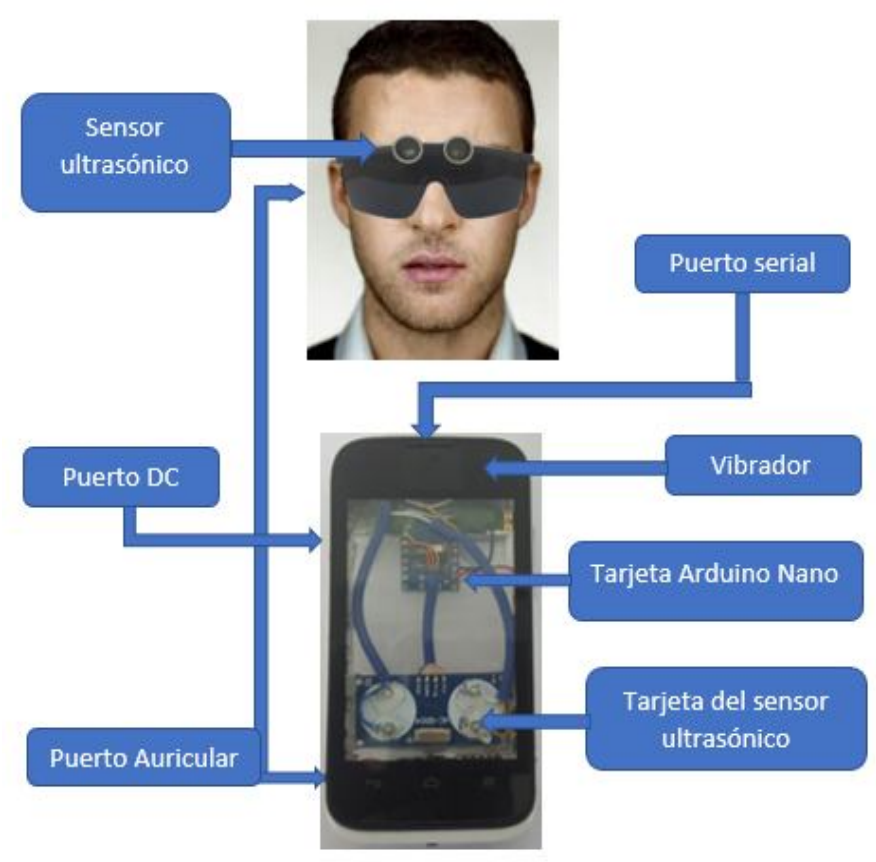

Figure 5: Device architecture

We used basically the same architecture, the same idea for the development of this, we used the housing of a cell phone to 
develop the device and have more reliability and security in Figure 6 we see the complete prototype.

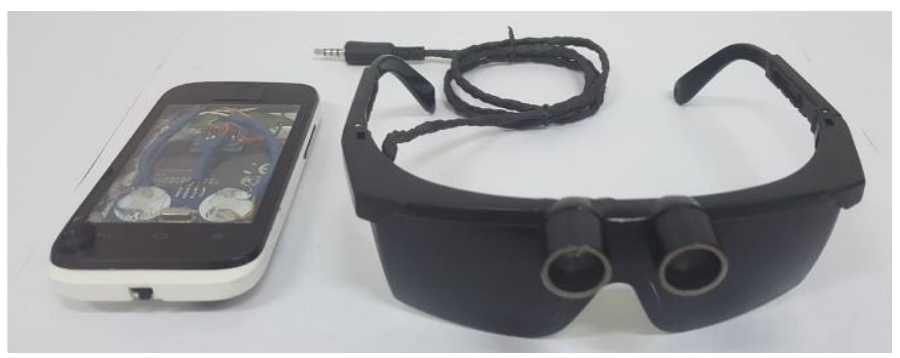

Figure 6: Complete prototype

\subsection{System analysis}

The ultrasound sensor used is the reference sensor HC-SR04 which has an average range of 2 meters. The operation of the sensor is based on an echo system, in addition the ultrasonic sensor throws 8 waves of $40 \mathrm{kHz}$ and the echo signal is set high until the bounce of the waves is received. Knowing that the speed of sound in air is approximately $340 \mathrm{~m} / \mathrm{s}$ and knowing the time it has taken for the wave to go and return, the distance is calculated.

The formula used to measure the target at the distance necessary for our purpose is Time $=2 \mathrm{D} / \mathrm{V}$ and Distance $=$ $\mathrm{V} * \mathrm{~T} / 2$. The sensor is located in the central part of the fixed target with a high pressure clip capable of resisting falls, another detail to consider is the use of the electronic sound device (buzzer), the prototype was made with a long cable so that the person can place it in the most convenient place since the excessive use of this sound can cause damage to blind people, according to the research of [11]. In our project we thought of implementing the use of headphones to reduce outside noise in the environment, however, seeing that the excessive use of headphones has irreversible consequences for health and hearing loss, we also used a sound device with high tones so that the noise could be reduced and not be so harmful to blind people.

As we can see in Figure 7 does not indicate the range in decibels of noise from a simple whisper to a rock concert, the allowed range of decibels is between 30 and 80 when passing this limit, it can have consequences such as developing a brain tumor or hearing loss [12].

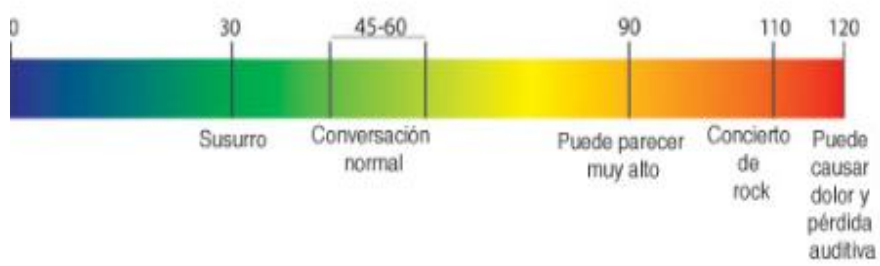

That is why our device has an acceptable noise of 80 decibels maximum as shown in Figure 8, therefore it would not cause major problems as previously named.

\section{Relación distancia vs ruido}

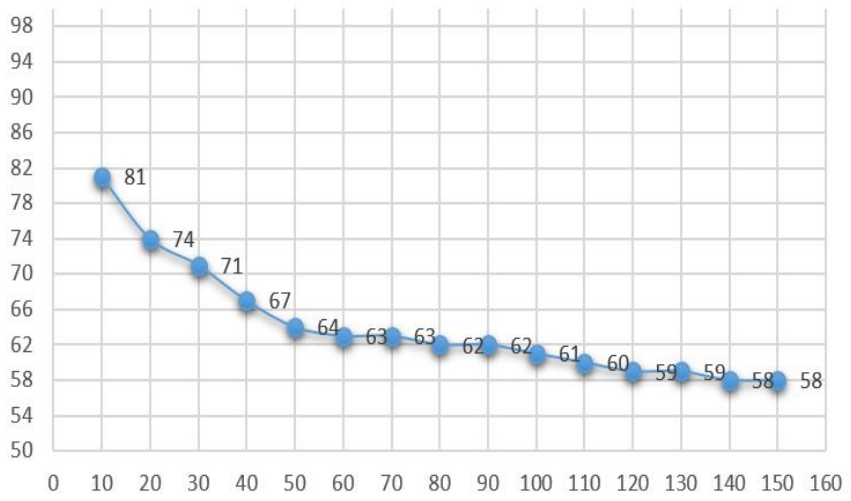

. Figure 8: Distance vs Sound Graphics

\section{RESULT}

The implementation of this design was achieved, after which tests were carried out in safe areas simulating a normal day of a blind person. As we can see in Figure 9 the sound is related to the distance, that is, the shorter the distance from the obstacle the greater the sound intensity, since the maximum value in $\mathrm{dB}$ that can be generated with this device is in the range of 80 to $90 \mathrm{Db}$.

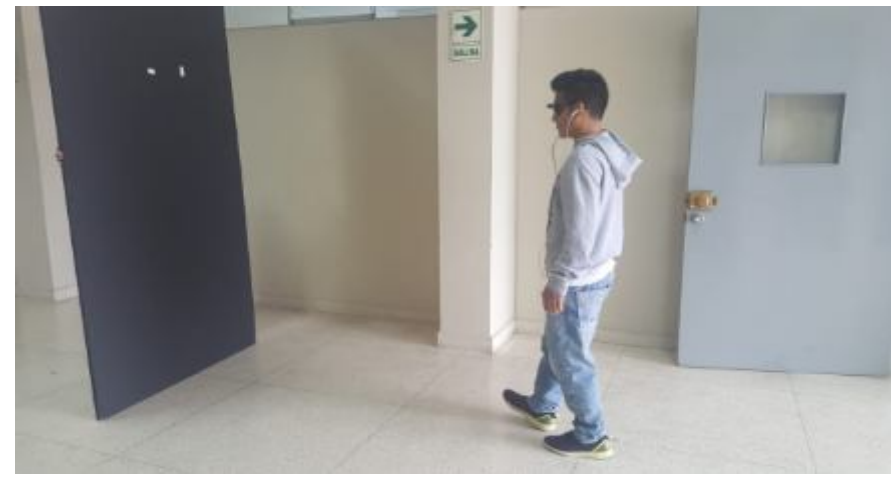

. Figure 9: Distance vs Sound Graphics

The subject walks through the passageway and encounters an obstacle $150 \mathrm{~cm}$ away, so the device detects it and starts to sound. For this purpose, tests were carried out at different distances obtaining a distance relation with the noise in $\mathrm{dB}$ as shown in Table 2. In this table are compiled the measured data, this data we take to an analytical part to determine what is the relationship between distance and noise.

. Figure 7: Noise range allowed 
Fredy Criollo-Sánchez et al., International Journal of Emerging Trends in Engineering Research, 8(8), August 2020, 4394 - 4398

Table 2: Distance vs sound measurement data

\begin{tabular}{|c|c|c|}
\hline & Distance $(\mathrm{cm})$ & DB \\
\hline 1 & 150 & 58 \\
\hline 2 & 140 & 58 \\
\hline 3 & 130 & 59 \\
\hline 4 & 120 & 59 \\
\hline 5 & 110 & 60 \\
\hline 6 & 100 & 61 \\
\hline 7 & 90 & 62 \\
\hline 8 & 80 & 62 \\
\hline 9 & 70 & 63 \\
\hline 10 & 60 & 63 \\
\hline 11 & 50 & 64 \\
\hline 12 & 40 & 67 \\
\hline 13 & 30 & 71 \\
\hline 14 & 20 & 74 \\
\hline 15 & 10 & 81 \\
\hline
\end{tabular}

\section{CONCLUSION}

In this investigation it is demonstrated that the use of the device is of great help but that still it has some difficulties as it is the tracking of some elements that still do not manage to process them with facility, nevertheless this work can be improved and be presented in a following investigation with optimal results when some imperfections are improved. We can conclude by saying that this device is a great alternative that would benefit many people in addition to the device would be easy to acquire for being low cost and simple to use.

\section{REFERENCES}

1. B. Campos, A. Cerrate, E. Montjoy, V. Dulanto, C. Gonzales y A. Tecse, Prevalencia y causa de ceguera en Perù: encuesta nacional, Panamericana de salud pùblica, p. 253, 2014.

2. J. C. Suárez Escudero, discapacidad visual y ceguera en el adulto,MEDICINA U.P.B, vol. 30, $\mathrm{n}^{\circ}$ 2, pp. 170-180, 2011.

3. S. wawan, Development of glasses for guiding visually impaired using ultrasonic sensor and microcontroller, Journal of Multidisciplinary Engineering Science and Technology, vol. 1, no 5, pp. 1-3, 2014.

4. S. D. Ontiveros Paredes, D. Rojas Balbuena y J. Martines Paredes, Diseño y construccion de un baston blanco electronico para personas invidentes, cientifica, vol. 18 , $\mathrm{n}^{\circ} 2$, p. 65, 2014.

5. TecnoGaming Labs, Arduino nano, patagoniatec, Argentina, 2015.

6. AG Electronica, MB0016: OEM ARDUINO NANO V3.0, AG Electronica, Republica del Salvador, 2017.
7. J. A. B. Susa, M. A. F. Malbog, J. N. Mindoro, C. D. Casuat, and A. S. Alon, Automatic room humidifier and dehumidifier controller using arduino uno, Int. J. Adv. Trends Comput. Sci. Eng., vol. 9, no. 2, pp. 2208-2212, 2020.

https://doi.org/10.30534/ijatcse/2020/198922020

8. Supriyono, I. Mawardi, and W. A. Siswanto, The development of engine control module manipulator module based on arduino to increase power and torque of motorcycle engine, Int. J. Adv. Trends Comput. Sci. Eng., vol. 8, no. 6, pp. 3135-3139, 2019. https://doi.org/10.30534/ijatcse/2019/76862019

9. CURSO ARDUINO, Tutorial 13: Modulo sensor ultrasonico;haz una alarma, PROSERQUISA DE C.V, 2016.

10. S. Londoño, Catergoria Arduino, SomosMakers.cl, 2017.

11. M. M. GALARZA MUÑOZ, CÓMO INCIDE EL DESCONOCIMIENTO DE LOS DAÑOS QUE CAUSA A, UNIVERSIDAD DE GUAYAQUIL, vol. I, $\mathrm{n}^{\circ}$ 1, p. 20, 2016.

12. CDC, Pérdida auditiva en los niños, CDC. Centros para el Control y la Prevención de Enfermedades. Salvamos vidas. Protegemos a la gente., vol. I, n ${ }^{\circ}$ 1, p. 1, 2017. 